\title{
HERMENÊUTICA E DIREITO: O DASEIN NA FILOSOFIA HERMENÊUTICA DE HEIDEGGER
}

\author{
Cleyson de Moraes \\ Mello $^{1}$
}

Vanderlei Martins ${ }^{2}$

\begin{abstract}
Resumo
A Constituição de 1988 representa uma mudança de paradigma no Direito brasileiro. A partir dessa mudança de modelo, é necessário investigar a realização do direito, a partir da tutela da dignidade da pessoa. O Direito alinhado a hermenêutica filosófica assume, pois, um viés transformador. Daí a necessidade de compreender o Direito a partir do ser-no-mundo. O pensamento jurídico não pode ser concebido a partir de um predomínio causado pelos limites da razão e edificado com os poderes da racionalidade abstrata. É, neste sentido que, em face da flagrante inefetividade da hermenêutica clássica, originariamente metodológica, torna-se necessária à construção de uma resistência teórica que aponte para a construção das condições de possibilidade da compreensão do direito, como modo de ser-no-mundo.
\end{abstract}

Palavras-chave: Direito. Dignidade humana. Ser-no-mundo, Dasein.

\section{INTRODUÇÃO}

Pensar o Direito em sua forma mais originária. Este é o desafio em direção às sendas da realização da proteção da personalidade e a tutela da dignidade da pessoa humana. É um pensar o Direito com as lentes voltadas para o mais essencial: a dignidade humana como valor fundamental da Constituição da República (art.1 ${ }^{\circ}$, III, da CRFB/88).

O "saber" jurídico não pode ficar atrelado ao ente, dominado pela sua estrutura, mas sim deve caminhar sempre para além deste, ultrapassando-o, constantemente. O operador jurídico deve procurar superar o texto da lei, em busca do seu fundamento - em direção ao ser. O saber essencial do Direito não está posto, não é algo dado, objetificado (entitativo), mas sim desvelado ao julgador na análise do caso concreto decidendo. É um "saber" essencial que passa por cima do ente e procura atingir a sua forma mais originária. Somente

\footnotetext{
${ }^{1}$ Professor Adjunto da Faculdade de Direito da Universidade do Estado do Rio de Janeiro - UERJ; Advogado; Membro do Instituto dos Advogados Brasileiros - IAB. E-mail: profcleysonmello@ hotmail.com 11121151 vol.09, n. 03, Rio de Janeiro, 2016. pp. 1443
} 
quando ultrapassamos o ente, em busca do seu ser, as "proposições" jurídicas terão alguma justificação.

Nesse contexto, Heidegger (1995, p.94-95), na obra Sobre o Humanismo, afirma que:

Somente na medida em que o homem, ec-sistindo na Verdade do Ser, pertence ao Ser, é que pode provir do próprio Ser a recomendação das prescrições que tornar-se-ão para o homem lei e regra. Em grego, recomendar é némein. $\mathrm{O}$ nómos não é apenas a lei, porém, mais originalmente, a recomendação protegida pelo destinar-se do Ser. Só essa recomendação pode dispor o homem para o Ser. E somente essa disposição pode trazer e instaurar obrigações. Do contrário, toda a lei permanecerá e continuará apenas um produto (das Gemächte) da razão humana. Mais essencial para o homem do que todo e qualquer estabelecimento de regras é encontrar um caminho para a morada da Verdade do Ser. ${ }^{3}$

O esquecimento da Verdade do Ser em favor da "coisificação" do Direito, não pensado em sua essência, é o sentido de sua decadência. Sem a percepção desta essência todo o esforço e o cuidado para se "dizer o direito" transborda no vazio. As normas jurídicas em abstrato devem ganhar mais plenitude e colorido se considerarmos os estudos avançados de hermenêutica jurídica e concretude judicial, uma vez que aquela deixa de ser considerada como hermenêutica de orientação metodológica-científica (modo de conhecer) para ser estudada como hermenêutica ontológica (modo de ser).

O pensar usual (pensar o ente) dos operadores do direito é aquele em que a personalidade humana não é considerada como vetor máximo do ordenamento jurídico, senão como aptidão de ser titular de direitos e deveres, conforme prescreve o artigo $1^{\circ}$ do Código Civil, ou seja, considerada como sinônimo de capacidade jurídica. Ao contrário, a compreensão da personalidade jurídica deve se dar em duas vertentes: a primeira, como a possibilidade de ser sujeito de direitos e deveres e a segunda, e mais relevante, como o sentido existencial do próprio ser humano, visto como valor fundamental de nosso ordenamento jurídico. Neste caso, é o princípio da dignidade da pessoa humana ressoando em sua mais nobre originalidade (MELLO, 2007, p. XXII).

A dificuldade da compreensão do Direito a partir da sua forma mais originária reside, de certa forma, no despreparo e na incapacidade da maioria de nossa comunidade acadêmica de enfrentar os fundamentos do direito. É, pois, necessário colocar o Direito no caminho de sua origem ou nos desviarmos dele a partir de interpretações equivocadas.

Fazer do direito posto uma verdade, isto significa certamente fazer uma superação do texto normativo (algo dado), uma "personalidade". O encobrimento do ser do direito é fruto de

\footnotetext{
${ }^{2}$ Professor Adjunto da Faculdade de Direito da Universidade do Estado do Rio de Janeiro, em Regime de Dedicação Exclusiva. Atua na área de Ciências Sociais Aplicadas. E-mail: martins1951 @ yahoo.com.br ${ }^{3}$ HEIDEGGER, Martin. Sobre o Humanismo. Tradução de Emmanuel Carneiro Leão. 2.ed. Rio de Janeiro: Tempo Brasileiro, 1995, p.94-95.
} vol.09, n. 03, Rio de Janeiro, 2016. pp. 
uma tradição liberal-individualista-normativista no qual o Código Civil sempre desempenhou uma referência normativa predominante e exclusiva no recinto das relações interprivadas.

A cultura jurídica operada em salas de aula e nos tribunais de justiça deve ser desconstruida (visão de um sistema fechado codicista) em busca de uma postura mais aberta, prospectiva que dê suporte a uma sociedade complexa e pluralista. Isso não quer dizer que o julgador desconsidere a segurança jurídica e passe a decidir de forma arbitrária (neste caso, estaríamos diante de um Estado-Judiciário). Pelo contrário, a jurisprudência deve reconhecer a eficácia normativa dos princípios constitucionais no âmbito das relações jurídicas de direito privado, bem como recorrer à hermenêutica jurídica não como um conjunto de métodos (hermenêutica metodológica), mas sim como condição de possibilidade (hermenêutica filosófica). É a reconstrução do direito civil a partir do como hermenêutico, ou seja, um locus hermenêutico com fincas no princípio fundante da proteção da dignidade da pessoa humana. É o poder ser acerca das realidades humanas e pessoais.

A personalidade jurídica não pode ser considerada como um reduto do poder do indivíduo, mas sim "como valor máximo do ordenamento, modelador da autonomia privada, capaz de submeter toda a atividade econômica a novos critérios de legitimidade" (TEPEDINO, 2002, p. XXV).

A dogmática jurídica não pode esconder as vicissitudes da realidade material (mundo vivido) que o Direito deve tutelar, em especial, nas questões diretamente relacionadas ao Homem, sua dignidade e personalidade.

Este é o enorme desafio do jurista no início do século XXI: saber e conhecer o que seja o Homem, o que é a pessoa humana, sua dignidade e personalidade jurídica.

$\mathrm{Na}$ esteira da filosofia existencialista, a personalidade humana deve ganhar status de valor jurídico de cunho existencialista, já que esta não pode ficar aprisionada ao rol de direitos subjetivos típicos adotado pelo Código Civil. Daí a importância do entrelaçamento principiológico entre o direito civil e os direitos humanos.

$\mathrm{Na}$ verdade, tais questionamentos caminham para uma oportuna (re)fundamentação do pensamento jurídico. Sem focar o Direito na dignidade da pessoa humana, como pode o operador do direito aplicar as regras do direito posto? O primeiro passo é, pois, conhecer a dimensão ontológica do Direito.

A partir desse novo locus hermenêutico, a relação jurídica deve ser compreendida como a realização do Direito, inserida no seu contexto histórico-cultural, ou seja, a idéia de relação jurídica deve estar em harmonia com os direitos fundamentais, com vistas a repersonalização da pessoa. É a realização do direito conduzida por uma questão prévia: a vol.09, n. 03, Rio de Janeiro, 2016. pp. 
sintonia do Direito com os cânones da tutela da dignidade da pessoa humana. Daí a necessidade de uma nova racionalidade a partir de uma perspectiva ontológico-existencial (MELLO, 2006).

Melhor dizendo: é a possibilidade de análise do fenômeno jurídico a partir de suas vicissitudes totalitárias concretas no mundo da vida. É a relação jurídica ajustada a uma nova dinâmica social de inter-relação humana vista a partir de suas especificidades concretizantes. É o Direito inserido na pós-modernidade.

É justamente por isso que os operadores do direito precisam ajustar a dogmática jurídica ao novo, ao efêmero, ao poder-ser, a diversidade, à diferença, ao pluralismo, bem como enfrentar as relações jurídicas civilísticas a partir de sua dinamicidade espaço-tempo cultural.

O jurista não pode fechar os olhos para esta nova realidade, refugiando-se num formalismo positivista que prescinda de aproximações com a hermenêutica filosófica e constitucional.

É desta forma que o Direito não pode se ancorar no paradigma epistemológico da filosofia da consciência e na subjetividade. Observa-se a entificação do Direito. O Direito deve restar harmonioso com o modo de ser-no-mundo (mundo da vida). Dessa maneira é possível reconhecer o fundamento da concretização normativa desejada.

O pensamento jurídico não pode ser concebido a partir de um predomínio imposto pelos limites da razão e edificado com os poderes da racionalidade abstrata. A transcendência existencial torna-se uma alavanca de evolução da ciência jurídica, já que a concretização normativa ficará garantida através dos pilares do círculo hermenêutico.

A superação da filosofia da consciência, da relação sujeito-objeto, do subjetivismo, é à busca do homem em sua essência, como possibilidade e modo de ser-no-mundo, ou seja, é o caminho em direção a uma humanização do Direito. É o caminho para a (de)sentificação do Direito, já que um ente não pode fundar os entes. É a partir da hermenêutica como modo de ser-no-mundo que o Direito deve procurar caminhar por uma área de valores humanos peculiares, subtraídos à lógica formal do direito positivo. ${ }^{4}$

O Direito é um sendo, é um acontecer, é uma abertura de possibilidades. O ser deve ser compreendido a partir do homem em seu próprio acontecer, historicamente situado. A

\footnotetext{
${ }^{4}$ Nessa linha de pensamento, Gianni Vattimo afirma que "se é verdade que é preciso procurar obter também no campo das ciências humanas uma forma de rigor e de exatidão que satisfaça as exigências de um ser metódico, isto deve fazer-se desde que se reconheça o que existe no homem de irredutível e peculiar; e esse núcleo é o humanismo da tradição, centrado em torno da liberdade, da escolha, da imprevisibilidade do comportamento, isto é, da sua constitutiva historicidade." (VATTIMO, 1987. p.32). 
hermenêutica, com o viés da ontologia fundamental, procura interrogar o ser por meio da historicidade e da temporalidade do ser-aí, ou seja, compreender a questão do ser fora do contexto da tradição metafísica.

Desse modo, é a partir do pensar originário que a ciência jurídica vai desdobrando o seu jogo de preceitos legais. No viço dessa originalidade, pensar o Direito quer dizer: vir e chegar à plenitude de ser no Direito é a clareira, aletheia; é a essência do pensamento jurídico em seu desvelar-se, em seu dar-se originário. Vê-se, pois, a produção do Direito e não, simplesmente, a sua (re)produção jurídica. É essa operação do pensamento jurídico que possibilita a sua renovação pela (re)fundamentação de seu ser.

A compreensão é a própria abertura do ser-no-mundo, bem como é um existencial. Todo o compreender é derivado dessa compreensão existencial, que é a própria luz, iluminação, abertura, clareira, revelação do ser-aí, Aletheia.

O Direito deve ser compreendido de modo originário e autêntico, desvinculado dos conceitos ingênuos e opiniões que a tradição em si as carrega. Há que se buscar uma abertura mais abrangente e mais originária do Direito.

\section{A DIGNIDADE DA PESSOA HUMANA COMO DISCURSO LEGITIMADOR DO DIREITO}

É certo que na civilização moderna o conceito de pessoa brilha como estrela de primeira grandeza em seus mais diversos matizes nos campos da Moral, do Direito, da Filosofia, da Antropologia, da Sociologia, da Psicologia, da Religião, etc. Daí as diversas linhas teóricas e paradigmas que possuem como epicentro o conceito de pessoa. Nesta perspectiva torna-se difícil à busca de uma definição precisa acerca da dignidade da pessoa humana, em especial, na seara jurídica.

Na filosofia moderna, duas linhas teóricas condicionam-se mutuamente:

É a reformulação do conceito de pessoa no campo conceptual da metafísica da subjetividade, intentada por Descartes e pelos cartesianos, que é o alvo da crítica empirista; e é a polêmica com essa crítica que leva Kant a um último e mais radical aprofundamento da concepção de pessoa em direção ao terreno da subjetividade absoluta. Na verdade, de Descartes a Kant e de Hobbes a Hume o conceito de pessoa oscila entre a unidade da consciência-de-si e a pluralidade das representações do $\mathrm{Eu}$, aquela primeira e originária, essas coordenadas nominalisticamente nas múltiplas designações de que a pessoa é objeto. (VAZ, 2003, p.195)

Portanto, que é o homem? A despeito da interrogação filosófica sobre o homem no correr dos séculos, aqui, adotar-se-á o paradigma heideggeriano, ou seja, é na dimensionalidade do Dasein que a dignidade da pessoa humana e a sua personalidade se 
desvelarão, uma vez que neste espaço o homem não é um ente, senão o aí-do-ser. É um novo paradigma de fundamentação do direito, já que pautado na dimensionalidade ontológica da pessoa humana.

Hoje em dia, o dizer o Direito nos chega por meio de um pensamento jurídico alienante e silente, pautado em um positivismo legalista.

Angustiante por natureza, a busca desenfreada pela segurança jurídica sufoca cada vez mais o pensar original. Um sistema jurídico axiologicamente neutro, a-temporal, a-histórico já representa um perigo a ser evitado e uma ameaça a ser controlada pelos juristas. Caso contrário, imperar-se-á por toda a parte uma atitude de subserviência ao texto legal, representando, assim, a inautenticidade do Direito, isto é, a reificação do direito. Isso representa uma prestação jurisdicional restrita às atividades lógicas, científicas, cuja visão objetivista dos entes está em distonia com o mais digno de ser pensado, qual seja: o pensar o ser e a verdade da faticidade do ser-aí.

Dessa maneira o estatuto legitimador do Direito não será mais de cunho objetivista. Uma espécie de antropologia da faticidade abre-se como único lugar para a problematização do homem e da filosofia (STEIN, 2003, p.16). E por que não dizer do Direito? É, pois, um novo plano para se dizer o Direito em que se dão ente e ser, no nível do ente privilegiado. É a filosofia de Hedeigger ancorada nos teoremas da diferença ontológica e círculo hermenêutico. É neste nível que o Direito passa a receber seu estatuto legitimador.

Caberá, pois a jurisdição constitucional enfrentar as questões acerca da natureza da dignidade da pessoa humana a partir das especificidades dos casos concretos decidendos (concretude judicial), a partir de uma (re)fundamentação do pensamento jurídico.

A dignidade da pessoa humana deve ser reconhecida pelo Direito, não como questão de validade da norma jurídica, senão como sentido do ser, como algo preexistente e anterior a todo fenômeno jurídico. É uma espécie de a priori do conhecimento na ontologia como hermenêutica da faticidade, como analítica existencial. É, pois, o Dasein como ser-no-mundo, como pressuposto de qualquer teoria do conhecimento ou fenômeno jurídico.

A dignidade é intrínseca a todo e qualquer ser humano. Neste sentido, o artigo $1^{\circ}$ da Declaração Universal da ONU (1948) determina que "todos os seres humanos nascem livres e iguais em dignidade e direitos. Dotados de razão e consciência, devem agir uns para com os outros em espírito e fraternidade."

Em Ser e Tempo, Heidegger (2002, p.33) chama a atenção, logo no início, para a importância da compreensão pré-ontológica do ser. O filósofo diz que "esse ente que cada um de nós somos e que, entre outras, possui em seu ser a possibilidade de questionar, nós o vol.09, n. 03, Rio de Janeiro, 2016. pp. 
designamos com o termo pre-sença. A colocação explícita e transparente da questão sobre o sentido do ser requer uma explicação prévia e adequada de um ente (pre-sença) no tocante ao ser ser."

Heidegger (2002, p.309) afirma que Dasein (pre-sença, ser-aí) "não é sinônimo nem de homem, nem de ser humano, nem de humanidade, embora conserve uma relação estrutural. Evoca o processo de constituição ontológica de homem, ser humano e humanidade.” Dessa forma, é no Dasein que o homem constrói o seu modo de ser, a sua existência, a sua história.

A compreensão da dignidade da pessoa humana não é uma compreensão empírica de algo enquanto algo, e sim condição de possibilidade desta última.

É necessário, pois, que o elemento nuclear da noção de dignidade da pessoa humana seja reconduzido a uma matriz heideggeriana, cujo ser-no-mundo é constituição necessária e fundamental do Dasein. É um existencial.

\section{DIGNIDADE E HUMANIDADE: A NECESSIDADE DE ULTRAPASSAMENTO DO ANIMAL RATIONALE EM DIREÇÃO A SUA EC-SISTÊNCIA}

O esquecimento da Verdade do Ser em favor da avalanche do ente, não pensado em sua essência, é o sentido da "decadência", mencionada em Ser e Tempo. Da mesma forma, o esquecimento da tutela da dignidade humana em favor da idéia minimalista do homem-objeto, é o sentido da "decadência" do Direito.

A metafísica pensa o homem a partir da animalitas. Ela não o pensa na direção de sua humanitas. (HEIDEGGER, 1995, p.40). É dessa maneira que Heidegger (1995, p.41) remete o ser humano para o lugar da compreensão do ser. Em Sobre o Humanismo, o filósofo afirma que "só se pode dizer ec-sistência da Essência do homem, isto é, do modo humano de "ser", pois somente o homem, até onde alcança a nossa experiência, foi introduzido no destino da ecsistência.” (HEIDEGGER, 1995, p.41).

Heidegger (1995, p.41) chama a ec-sistência do homem, o estar na clareira do Ser. "Esse modo de ser só é próprio do homem. Assim entendida, a ec-sistência não é apenas o fundamento de possibilidade da razão, ratio. É também onde a Essência do homem con-serva a proveniência de sua determinação."

Assim, o que o homem é repousa em sua ec-sistência. A ec-sistência em Heiddeger (1995, p.43-44) não se identifica com o conceito tradicional de existentia. Ele afirma que "Kant apresenta a existentia como sendo realidade, no sentido de objetividade da experiência. Hegel determina a existentia, como a idéia da subjetividade absoluta, que se sabe a si mesma. vol.09, n. 03, Rio de Janeiro, 2016. pp. 
Nietzsche concebe a existentia, como o eterno retorno do mesmo."

Dessa maneira, na esteira da concepção heideggero-gadameriana, a dignidade da pessoa humana deve ser pensada no âmbito da "compreensão do Ser", isto é, a partir da analítica existencial do "ser-no-mundo". Na concretude judicial, a partir das circunstâncias do caso concreto decidendo, sempre que o indivíduo for considerado como objeto cognoscível (como ente - direito coisificado), a sua dignidade será atingida de forma inequívoca.

É neste sentido que doutrina e jurisprudência possuem papel relevante nessa mudança de postura. A noção de dignidade da pessoa humana vai se conformando, a partir do momento em que o Direito é desvelado a partir da ec-sistência. Pois é ec-sistindo que o homem pode pensar a Verdade do Ser. A ec-sistência do homem é uma ec-sistência Histórica. (HEIDEGGER, 1995, p.59). O que se percebe é a necessidade de contextualização históricocultural da dignidade da pessoa humana.

Os princípios que permeiam a dignidade da pessoa humana estão fincados no rol dos direitos da personalidade, bem como ancorados no conjunto de direitos fundamentais, de tal sorte que, caso ocorra (des)respeito pela vida, pela integridade psicofísica, pela moral, ou imagem do ser humano, ou suas condições mínimas de existência sejam violadas estar-se-á diante da violação da dignidade da pessoa humana.

O Ser não pode ser pensado partir do ente, tal qual a metafísica do "esquecimento do ser”. A Verdade do Ser, como a própria clareira, permanece oculta à metafísica. Heidegger (1995, p.61) afirma que "o Ser se clareia para o homem no projeto ec-stático. Todavia, esse projeto não cria o Ser. Ademais, o projeto é essencialmente um projeto lançado. O que lança no projeto, não é o homem mas o próprio Ser. Esse destina o homem na ec-sistência do Dasein, como sua Essência.”

Heidegger procura "destruir" a metafísica ocidental, ancorada em concepções objetificantes, para introduzir uma relação entre ser humano e coisas que precede qualquer relação. É no viés ontológico que a compreensão do ser como Dasein supera os paradigmas objetificantes.

Neste contexto Heidegger (1995, p.78) afirma que:

Ora, o que uma coisa é, em seu ser, não se esgota em sua ob-jetividade e principalmente quando a ob-jetividade possui o caráter de valor. Toda valorização, mesmo quando valoriza positivamente, é uma subjetivação. Pois ela não deixa o ente ser mas deixa apenas que o ente valha, como objeto de sua atividade (Tun). O esforço extravagante, de se provar a objetividade dos valores, não sabe o que faz. Dizer-se que "Deus" é o "valor supremo", é uma degradação da Essência de Deus. Pensar em termos de valor é aqui - como alhures - a maior blasfêmia, que jamais se possa pensar com relação ao Ser. Pensar contra os valores não significa, por conseguinte, tocar os tambores da desvalorização (Wertlosigkeit) e da nulidade (Nichtigkeit) do ente mas vol.09, $\mathrm{n}^{\circ}$. 03, Rio de Janeiro, 2016. pp. 
significa: pro-pôr ao pensamento, contra a subjetividade do ente, como simples ob-jeto, a clareira da Verdade do Ser.

Dessa forma, o pensamento jurídico objetificante somente será superado a partir da (re)fundamentação do Direito. O fundamento se dá a partir do ser-no-mundo. Mundo é a clareira do Ser, a qual o homem se ex-põe por sua Essência lançada. Heidegger (1995, p.79) explica que o homem nunca é homem como um "sujeito" se referindo a objetos, de sorte que sua Essência esteja na relação sujeito-objeto. Ao contrário, o homem é, em sua Essência, primeiro ec-sistente na abertura do Ser.

Na esfera jurídica, ao se pensar o Direito, deve-se pensar a questão da Verdade do Ser, ou seja, pensar a humanitas do homo humanus. É no pensamento da ec-sistência do Direito que se deixa de lado a obliteração e arbitrariedade do julgador. A concretização da dignidade da pessoa humana nesta perspectiva caminha na direção da Essência do homem, isto é, na direção da Verdade do Ser (o homem mais do que o animal rationale). É, pois, o humanismo do Direito que pensa a humanidade do homem na proximidade do Ser.

Daí que o substrato material da dignidade da pessoa humana somente será desvelado se o operador do direito caminhar inicialmente em direção ao seu fundamento mais originário, qual seja: Dasein, ser-no-mundo, ser-aí, pre-sença. É a partir deste locus hermenêutico que se irradiam os preceitos e regras que orientará o homem, experimentado a partir da ec-sistência do Ser, historicamente situado.

Somente na ec-sistência do homem na Verdade do Ser é que o Direito poderá ser (des)velado de forma legítima constituindo o lugar originário de sua dignidade e personalidade.

A dignidade da pessoa humana é, pois, um sendo. Melhor dizendo: uma con-juntura, sempre de acordo com o destino Histórico do homem que mora na Verdade do Ser. Logo, a contextualização histórico-cultural da dignidade da pessoa humana é necessária e relativa. Vejamos alguns exemplos: a) a colocação de algemas em todo e qualquer indivíduo? b) a aplicação da pena "de cara para a parede" a todos os alunos travessos? c) a disponibilização das notas dos alunos nos corredores universitários? d) a impossibilidade de matrícula do aluno por falta de pagamento? e) o aborto nas questões da anencefalia? f) a questão do direito das famílias, em especial, a homoafetividade e a concepção do "poli-amor"? g) a questão da transfusão de sangue em relação às "testemunhas de Jeová"? h) o direito de morrer com "qualidade de vida"?

Neste caso, cabe a pergunta: a dignidade do homo humanus não estaria acima do multculturalismo? Seria o caso da adoção de um paradigma universal mínimo que traduzisse uma espécie de "invariantes ontológicas" ou "invarienates ec-sistentes"? já que em certas regiões atos atentatórios à dignidade humana são tidos como legítimos e suportados pela vol.09, nº. 03, Rio de Janeiro, 2016. pp. 
prática social.

\title{
HERMENEUTICS AND LAW: DASEIN IN THE HERMENEUTIC PHILOSOPHY OF HEIDEGGER
}

\begin{abstract}
The Constitution of 1988 represents a change of paradigm in the Brazilian law. From this change of model, it is necessary to investigate the performance of duty, from the protection of the dignity of the person. The Right aligned the philosophical hermeneutics is therefore a bias processor. Hence the need to understand the law from being-in-the-world (In-der-Welt-Sein). The legal thought cannot be designed from a predominantly caused by the limits of reason and built with the power of abstract rationality. It is in this sense that, given the striking ineffectiveness of classical hermeneutics, methodological in your origin, it is necessary to construct a theoretical strength that point to the construction of the conditions of possibility of understanding the law, as a way of being-in-the-world.
\end{abstract}

Keywords: right. human dignity. being-in-the-world, Dasein.

\section{REFERÊNCIAS}

HEIDEGGER, Martin. Sobre o Humanismo. Tradução de Emmanuel Carneiro Leão. 2.ed. Rio de Janeiro: Tempo Brasileiro, 1995.

Ser e Tempo. Parte I. Tradução de Márcia Sá Cavalcante Schuback. 12.ed. Petrópolis: Vozes, 2002, p.33.

MELLO, Cleyson de Moraes. Hermenêutica e Direito. Rio de Janeiro: Freitas Bastos, 2006.

Código Civil Interpretado. Rio de Janeiro: Freitas Bastos, 2007, p.XXII.

STEIN, Ernildo. Nas Proximidades da Antropologia: Ensaios e Conferências Filosóficas. Ijuí: Unijuí, 2003, p.16.

TEPEDINO, Gustavo. Crise de Fontes Normativas e Técnica Legislativa na Parte Geral do Código Civil de 2002. In: TEPEDINO, Gustavo. (Org.) A Parte Geral do Novo Código Civil - estudos na Perspectiva Constitucional. Rio de Janeiro: Renovar, 2002, p.XXV.

VATTIMO, Gianni. O Fim da Modernidade: Niilismo e Hermenêutica na Cultura PósModerna. Tradução Maria de Fátima Boavida. Lisboa: Presença, 1987. p.32.

VAZ, Henrique Cláudio Lima. Antropologia Filosófica II. 4.ed. São Paulo: Loyola, 2003, p. 195.

Trabalho enviado em 27 de março de 2016.

Aceito em 16 de junho de 2016. 
